Brief note

\title{
IDENTIFICATION OF THE CAUSE OF THE STEM NECK FRACTURE IN THE HIP JOINT ENDOPROSTHESIS
}

\author{
A.M. RYNIEWICZ ${ }^{*}$ and Ł. BOJKO \\ AGH University of Science and Technology \\ Faculty of Mechanical Engineering and Robotics \\ 30 Mickiewicz Ave., 30-059 Cracow, POLAND \\ E-mails: anna@ryniewicz.pl; lbojko@agh.edu.pl \\ A. RYNIEWICZ \\ Cracow University of Technology, Faculty of Mechanical \\ Laboratory of Coordinate Metrology \\ 37 John Paul II Ave., 31-864 Cracow, POLAND \\ E-mail: andrzej@ryniewicz.pl \\ P. PAŁKA \\ AGH University of Science and Technology \\ Faculty of Non-Ferrous Metals \\ 30 Mickiewicz Ave., 30-059 Cracow, POLAND \\ E-mail: pawel.palka@agh.edu.pl \\ W. RYNIEWICZ \\ Jagiellonian University Medical College \\ Faculty of Medicine, Dental Institute, Department of Dental Prosthodontics \\ ul. Montelupich 4, 31-155 Cracow, POLAND \\ E-mail:wojciech@ryniewicz.pl
}

\begin{abstract}
Endoprosthesis stem fractures are among the rarest complications that occur after hip joint arthroplasty. The aim of this paper is to evaluate the causes of the fractures of the Aura II stem neck, which is an element of an endoprosthesis implanted in a patient. In order to achieve it, a radiogram was evaluated, the FEM analysis was carried out for the hip joint replaced using the Aura II prosthesis and scanning tests as well as a chemical analysis were performed for the focus of fatigue. The tests performed indicate that the most probable causes leading to the fatigue fracture of the Aura II stem under examination were material defects in the process of casting and forging (forging the material with delamination and the presence of brittle oxides and carbides) that resulted in a significant reduction of strength and resistance to corrosion. In the light of an unprecedented stem neck fracture, this information should be an indication for non-destructive tests of ready-made stems aiming to discover the material and technological defects that may arise in the process of casting and drop forging.
\end{abstract}

Key words: prosthetic arthroplasty, stem construction, fatigue fracture, FEM (finite element method), SEM (scanning electron microscopy).

\section{Introduction}

Each year, the number of patients with a hip implant is growing. It is estimated that there are over 1.3 million of prosthetic arthroplasty surgeries carried out across the world each year. The prediction is that

\footnotetext{
${ }^{*}$ To whom correspondence should be addressed
} 
by 2030 , this number in the US will grow by $85 \%$. In Poland, according to the National Health System data, there were 41203 total hip and knee replacement surgeries carried out in 2009, while in 2010 the number went up to 42055 [1]. This procedure is a serious surgical intervention and involves a certain level of risk, but it may prevent disability in a patient. Physical activity after the total hip replacement surgery is not only possible but also recommended in order to preserve the agility of the operated joint and the patient's general condition [2-4]. The forms of exercise considered safe include walking, Nordic walking, cycling and swimming $[5,6]$. The data on the viability of specific prosthesis structures may be obtained in remote tests. There are also numerous registers of endoprostheses that may be helpful. One of the best registers is the Swedish Knee Arthroplasty Register [7, 8]. The data on the10-year survival rate it includes show that $94 \%$ of cement endoprostheses and $85 \%$ of non-cement endoprostheses of the hip joint implanted in 1992-2007 are characterised by good stability and do not require revision surgery [9]. To compare, the 15-year survival rate for the Alloclassic-Zweimüller endoprosthesis is at the level of $98 \%$, both for the acetabulum and the stem [10], according to Suckel. Endoprosthesis registers make it possible to evaluate risk factors and causes of failures. Remote tests indicate that the most common reasons for revision surgeries include: wear of the surface coming into tribological contact and aseptic loosening of the prosthesis stem and acetabulum. Endoprosthesis stem fractures are among the rarest complications (Fig.1). The fractures of the endoprosthesis stem together with the shaft of the femoral bone are reported more often while isolated distal fractures of endoprosthesis stems occur much less frequently [11-17]. The case described in the relevant literature was a fracture in a patient which occurred 23 years after the primary implant procedure. The case of a direct neck fracture, which is analysed below, occurred in a patient as soon as 6 years after the surgery (without mechanical injury).


Fig.1. Endoprosthesis stem fractures: a) with the shaft of the femoral bone (the material of the Faculty and Clinic of Orthopaedics and Musculoskeletal System Traumatology at the Silesian Medical University in Katowice), b) isolated distal part of the Weller endoprosthesis stem [11].

The probability of the fracture of a hip joint endoprosthesis stem is $0.27 \%$ [18]. In the literature available there is no description of the fracture of a stem neck, which is an extremely important construction element. Considering the requests of the individuals interested in the subject, the material submitted for examination, the rare occurrence of this complication and the scientific and social significance of the issue, the analyses carried out focused on the verification of the proposed thesis, i.e., that the fatigue fracture cause was a material defect resulting from the technological process and the absence of appropriate non-destructive strength tests performed for these important construction elements.

The aim of this paper is to evaluate the cause of the fracture of the Aura II stem neck, an element of the endoprosthesis implanted in a patient (male, 73), which occurred 6 years after the surgery.

\section{Material and methods}

The material under examination is the cemented Femoral Stem Aura II endoprosthesis (size 6 left, 542', 12-14 - material: Stainless Steel), reference number P0125006, batch number 0000372523, manufactured in October 2008, together with the Modular Head Component ( $28 \mathrm{~mm}, 12 / 14$, Taper, Plus 3,5 $\mathrm{mm}$, Neck, material: CoCr), reference number 53-131228, batch number 0000386265. The hospital 
discharge summary of 25 November 2008 includes information that the above described Aura II stem and head were the construction elements of the endoprosthesis which, together with the SHP HIP System Acetabular Cup $(28 \mathrm{~mm} \times 48 \mathrm{~mm})$, reference number 165921, batch number 1576940, were implanted in a patient on the basis of the diagnosis of epiphyseal aseptic necrosis of the femoral head of the left hip joint. On 16 October 2014, urgent revision surgery was performed in the patient because of a spontaneous fracture of the Aura II stem under examination. On the X-ray, there is a fracture of the stem neck on the left (Fig.2). The study method included the following procedures:

- the evaluation of the radiogram and the Aura II stem after removing it from the patient,

- the evaluation of the Aura II stem construction and its manufacturing technology,

- the distribution of stresses and dislocations using the FEM in the hip joint replaced with the Aura II system prosthesis,

- scanning tests of the stem neck fracture with the determination of the potential initiation zone,

- the elemental analysis in the focus of the fracture with the indication of a material and technological defect.

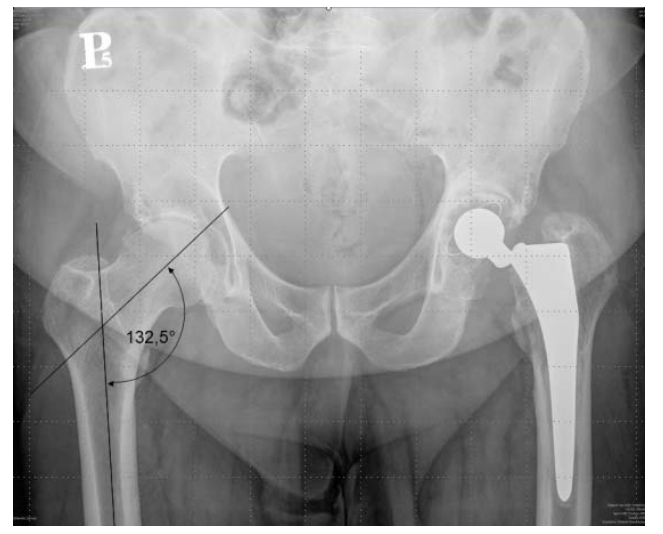

Fig.2. The X-ray image of the patient's hip zone at the Hospital Emergency Ward in 2014.

\section{Test results and discussion}

The analysed radiogram gives rise to certain doubts regarding the conditions of recreating the rotation axis of the implanted joint [19-21]. The rotation centre for the artificial joint is higher than the one for the natural joint. The tissue trauma could have caused a muscular contracture and some disturbances in the location of rotation centres for both joints. In the implant zone, there are no visible foci of osteolysis or loosening of the cement anchoring of the stem. The size of the stem is correct as, together with the cement, it fills the space between the inner walls of the cortical bone and the canal of the femoral bone. The location of the stem does not reveal any varus or vagus deformities. The anatomical angle between the head and the stem on the right is $132.5^{\circ}$, and the angle between the neck and the stem of the implanted Aura II stem is $137.5^{\circ}$. The size of the acetabulum is correct, too, without any evident signs of migration under the influence of locomotion stresses. The degree of the polyethylene acetabulum wear, measured using the distance of the dislocation between the centre of the endoprosthesis head and the centre of the acetabulum, is very small, below $0.1 \mathrm{~mm}$. An external visual evaluation of the polished surface of the stem reveals extensive zones of corrosion in the medial and lateral bending of the stem, in the proximal section and in the conical part contacting the head (Fig.3). Observations of metal construction elements removed from patients do not show such advanced corrosion changes as the ones confirmed in the stem under examination. On the external surface of the head, there are numerous circumferential scratches that are in stark contrast with the smooth and polished head which remained in contact with body fluids and does not show any signs of corrosion (Fig.4). Moreover, there is a circumferential crack, perpendicular to the neck axis, which starts $3 \mathrm{~mm}$ from the edge of the fracture and the place where the fatigue fracture was initiated. 
According to the information materials provided by the producer, the biomechanical evaluation of the Aura II stem construction is very good. The geometry of the Aura II stem is a result of anatomical studies of the proximal femur (Fig.5).

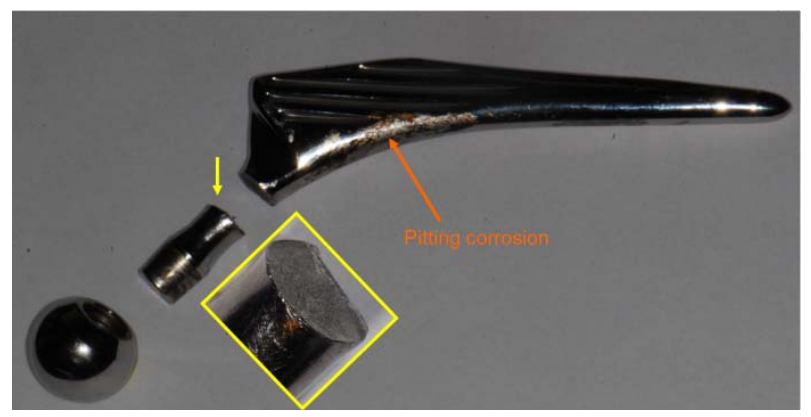

Fig.3. Fractured Aura II stem with the head removed from the patient's body.

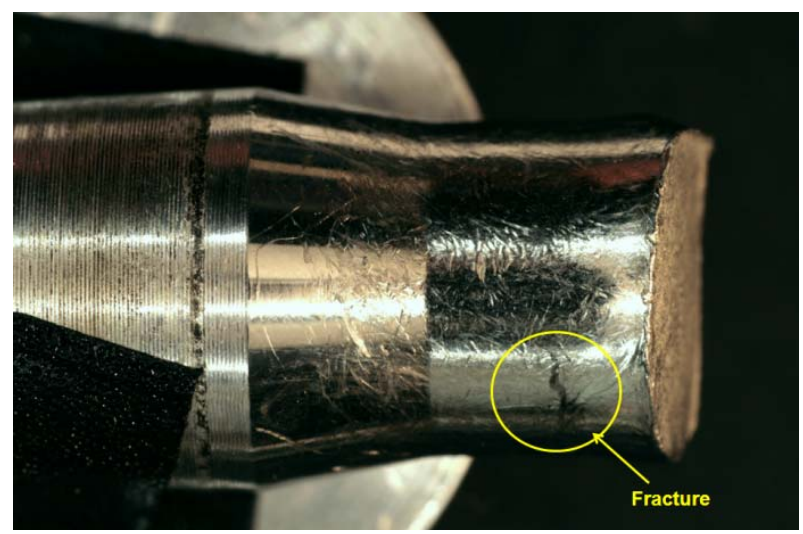

Fig.4. The surface layer of the fractured stem neck with numerous circumferential scratches and a crack in the close vicinity of the fracture initiation zone (focus).
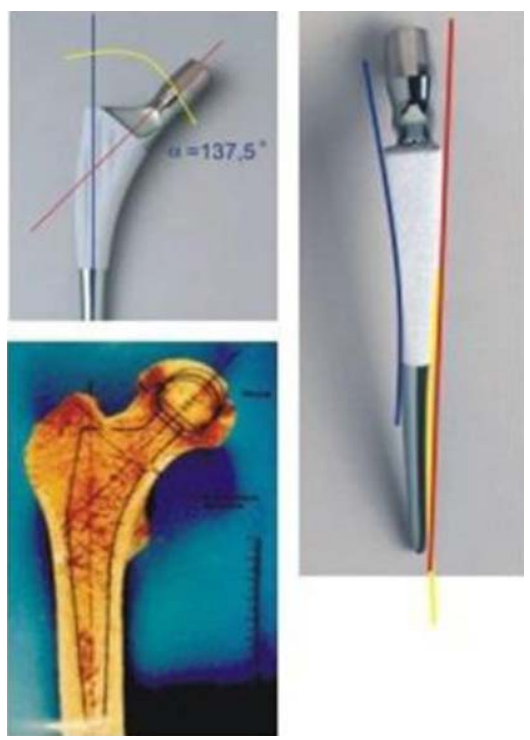

Fig.5. Aura II stem construction [22]. 
It is a combination of a self-locking, universal Müller-type stem with a standard geometry of an anatomical endoprosthesis. The difference in the curvature of the lateral surfaces of the stem enables it to adjust to the anatomy of the proximal epiphysis. In this way, the contact surface of the bone with the implant is greater. The stem neck has a narrowing, which limits the possibility of a conflict between the neck and the implant of the acetabulum and, at the same time, increases the movement range. The bend in the distal part reduces complications, such as femur pain at the end of the endoprosthesis stem. At the same time, Aura II preserves the properties of a self-centring and self-locking stem in the bone marrow canal. The Aura II stem is produced in a cement version and two non-cement versions. In each version, there are 18 types of stems available, 9 left and 9 right ones with an anteversion of 6 degrees. In the cement version, the stem is smooth, polished with vertical grooves in the proximal part in order to ensure better fixation in the bone cement.

The stem under examination is made of the M30NW austenitic steel which complies with the following standards: ISO 5832/9, BS 7252 part 9 and ASTM F 1586. According to the information provided by the producer, steel is obtained by melting, followed by the AOD (Argon Oxygen Decarburisation) process and meets the high standards required for orthopaedic implants. It has high resistance to corrosion and better mechanical properties than the 316L steel and it is non-magnetic (Tabs 1 and 2) [23]. After casting, the stem is formed in the plastic working process by drop forging. The process of forging and heat processing aims to reduce casting defects, recrystallisation and fragmentation, achieve uniform composition and eliminate porosity.

Table 1. M30NW Rods for implants - material composition.

\begin{tabular}{|l|l|l|l|l|l|l|l|}
\hline Element & $\mathrm{Fe}$ & $\mathrm{C}$ & $\mathrm{Cr}$ & $\mathrm{Ni}$ & $\mathrm{Mn}$ & $\mathrm{Mo}$ & $\mathrm{N}$ \\
\hline Weight, wt. \% & balance & $\leq 0.06$ & 21.00 & 9.00 & 4.00 & 2.20 & 0.40 \\
\hline
\end{tabular}

Table 2. M30NW Rods for implants -physical and mechanical properties.

\begin{tabular}{|c|c|c|}
\hline \multicolumn{2}{|l|}{ Parameter } & Value \\
\hline \multicolumn{2}{|l|}{ Density, $\mathrm{g} / \mathrm{cm}^{3}$} & 7.90 \\
\hline \multicolumn{2}{|c|}{$\begin{array}{l}\text { Coefficient of thermal expansion between } 20^{\circ} \mathrm{C} \\
\text { and } 200^{\circ} \mathrm{C}, \mu \mathrm{m} / \mathrm{m} \cdot{ }^{\circ} \mathrm{C}\end{array}$} & $16.6 \times 10^{-6}$ \\
\hline \multicolumn{2}{|c|}{ Young's modulus at $20^{\circ} \mathrm{C}, \mathrm{MPa}$} & $195 \times 10^{3}$ \\
\hline \multicolumn{2}{|c|}{ Thermal conductivity $20^{\circ} \mathrm{C}, \mathrm{W} \cdot \mathrm{m} / \mathrm{m}^{2} \cdot{ }^{\circ} \mathrm{C}$} & 14 \\
\hline \multicolumn{2}{|c|}{ Relative magnetic permeability } & $\leq 1.01$ \\
\hline \multirow{3}{*}{$\begin{array}{l}\text { Solution } \\
\text { condition }\end{array}$} & UTS, MPa & 860 \\
\hline & $\mathrm{YS}, \mathrm{MPa}$ & 450 \\
\hline & $\mathrm{E} \%(5 \mathrm{D}), \%$ & 40 \\
\hline \multirow{3}{*}{$\begin{array}{l}\text { Cold } \quad \text { worked } \\
\text { condition }\end{array}$} & UTS, MPa & $900 \div 1500$ \\
\hline & $\mathrm{YS}, \mathrm{MPa}$ & $850 \div 1200$ \\
\hline & $\mathrm{E} \%(5 \mathrm{D}), \%$ & $12 \div 15$ \\
\hline
\end{tabular}

The analyses and numerical FEM analyses performed for the global model of bone structures and the endoprosthesis including the Aura II stem with the CoCr head, ø $28 \mathrm{~mm}$, and the acetabulum, ø $28 \mathrm{~mm} \times 048$ $\mathrm{mm}$, indicate that the geometry of the stem secures the transfer of locomotion loads (Fig.6). The exemplary build-up of the stresses in the stem neck of the maximum value of $18 \mathrm{MPa}$ makes $5 \%$ of the possible load of this construction element considering the properties of the M30NW steel [24-28]. Maximum resultant microdislocations, of $0.05 \mathrm{~mm}$, do not cause destruction changes in the stem stabilisation zone. The fundamental goal of developing a load-bearing structure of the hip joint endoprosthesis is to ensure resistance to fatigue-induced destruction. The performance load on the endoprosthesis stem puts this construction element (replacing the lost function of the femoral neck) in the stress zone below the level of 
fatigue, which is the equivalent of the gigacycle fatigue range [29, 30]. It may be said that the stress values that occur during locomotion could not have caused fatigue-induced destruction.

What was the cause of the stem neck fracture? What additional circumstances brought about the notching effect and initiated the fracture? Direct observations indicate the presence of a defect in the stem neck (Figs 3, 4 and 7). The focus is visible in the fracture in both elements. On the external surface of the fractured neck, there is a deep scratch near the focus.

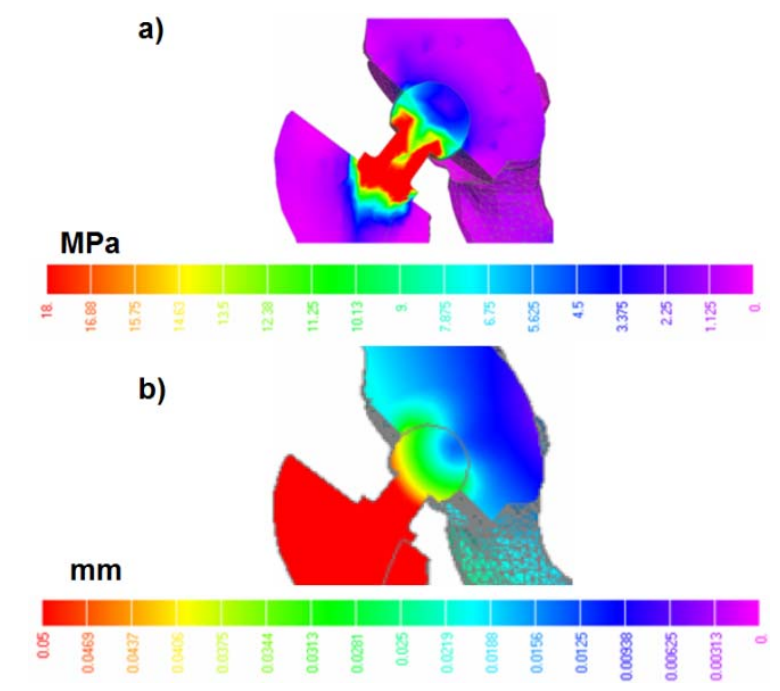

Fig.6. FEM calculations in the hip zone model with the Aura II prosthesis in the position of standing on two legs (vertical cross-section): a) map of reduced stresses, b) resultant dislocations.

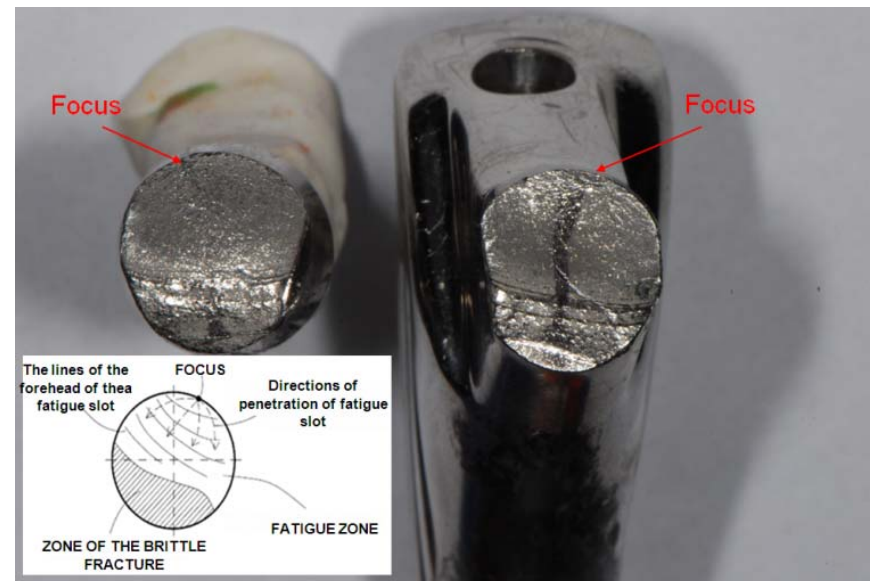

Fig.7. Surfaces of the stem neck fatigue fracture with the indication of the focus.

In the zone of the stem neck - the place of the technological defect - fatigue microcracks were initiated. Dislocation in the surface zone resulted in the creation of a slip plane and microcracks in the planes perpendicular to the load would develop into a macrocrack (Fig.7). The photograph shows the structures characteristic for a fatigue fracture: the focus, the focal zone, the fatigue zone, radial lines, the transition zone and the immediate fracture. The SEM analysis in the focus area may indicate that it was a defect which arose after forging, at the primary creation of the stem neck (Fig.8). It could be caused by microshrinkage that occurred in the manufacturing technology. There was a brittle fracture at the border of grains. The fracture was working and expanding in the physiological load conditions. The absence of stress relaxation at the top of the crack, because of the development of plastic deformations, caused further development of slip bands. The development of new slip bands resulted in further expansion of the crack and the rounding of its top. 
Releasing the load caused a sharp top of the crack and, as a result, the expansion of the crack in the next load cycle. Because of the oxidation of the structures revealed in contact with systemic liquids, the process of corrosion developed more effectively. In the object under examination, the plastic deformation zones in the shape of stripes are located parallel to the direction of the crack development. Still, they were deformed even more by mutual dislocation of the fractured stem. The initiation of the neck crack at the visible forged layer of the material was stimulated by the stresses and corrosion caused by the entry of systemic fluids into the area of the microcrack development. The presence of the forged material layer resulted in the build-up of stresses and was the cause of the stem neck fracture (Fig.9). In forged elements, a microcrack may develop at the border between the stem and the reinforced layer. Without a doubt, the responsibility for this defect falls on the stem producer. For this kind of elements, an individual evaluation of the technological process in nondestructive tests should be carried out. Numerous areas affected by pitting corrosion on the external surface of the stem might indicate that the material used for its construction did not comply with the requirement of high resistance to corrosion declared by the steel producer.

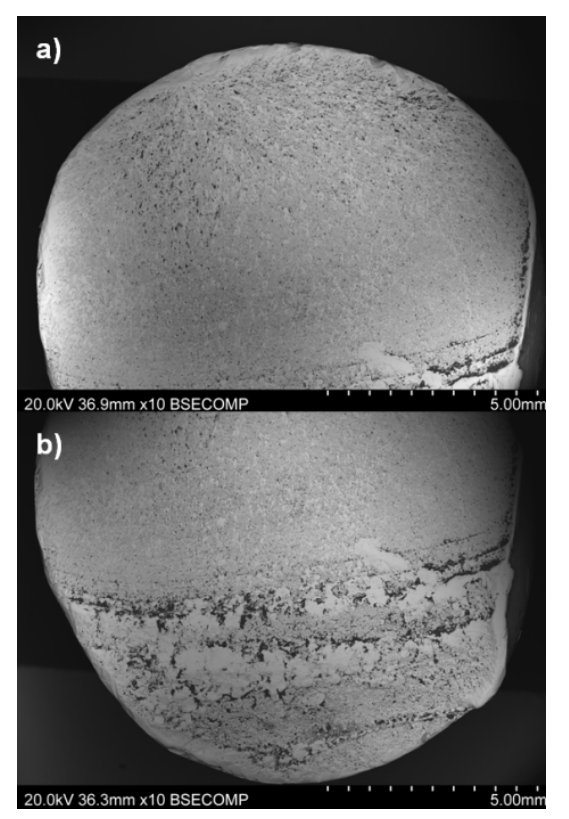

Fig.8. SEM images of the stem neck fatigue fracture in the ten-fold magnification: a) the area as seen from the focus, $b$ ) the fatigue zone and the immediate fracture zone.

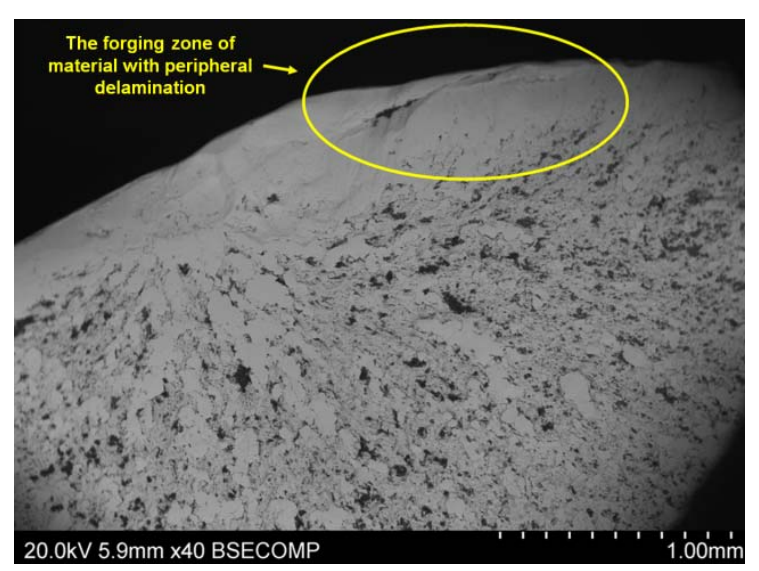

Fig.9. SEM images of the stem neck fatigue fracture with the location of the forging zone in the 40-fold magnification 
Table 3. Chemical composition in the forging zone - point 1 (the stem fragment as seen from the head).

\begin{tabular}{|l|l|l|l|l|}
\hline Element & $\begin{array}{l}\text { Weight } \\
(\text { wt. \%) }\end{array}$ & $\begin{array}{l}\text { Weight \% Error } \\
(\mathbf{1 - \sigma})\end{array}$ & $\begin{array}{l}\text { Atom } \\
(\text { at. \%) }\end{array}$ & $\begin{array}{l}\text { Atom \% Error } \\
(\mathbf{1 - \sigma})\end{array}$ \\
\hline $\mathrm{C}$ & 44.16 & 0.58 & 59.81 & 0.78 \\
\hline $\mathrm{N}$ & 12.9 & 2.68 & 14.97 & 3.11 \\
\hline $\mathrm{O}$ & 16.82 & 0.72 & 17.10 & 0.73 \\
\hline $\mathrm{Al}$ & 0.16 & 0.03 & 0.10 & 0.02 \\
\hline $\mathrm{Si}$ & 0.46 & 0.05 & 0.27 & 0.03 \\
\hline $\mathrm{S}$ & 0.41 & 0.11 & 0.21 & 0.06 \\
\hline $\mathrm{Cl}$ & 0.69 & 0.04 & 0.32 & 0.02 \\
\hline $\mathrm{K}$ & 0.35 & 0.03 & 0.14 & 0.01 \\
\hline $\mathrm{Ca}$ & 0.21 & 0.03 & 0.09 & 0.01 \\
\hline $\mathrm{Cr}$ & 5.79 & 0.17 & 1.81 & 0.05 \\
\hline $\mathrm{Mn}$ & 1.23 & 0.11 & 0.37 & 0.03 \\
\hline $\mathrm{Fe}$ & 14.03 & 0.33 & 4.08 & 0.09 \\
\hline $\mathrm{Ni}$ & 2.37 & 0.15 & 0.66 & 0.04 \\
\hline $\mathrm{Mo}$ & 0.42 & 0.29 & 0.07 & 0.05 \\
\hline & 100 & & 100 & \\
\hline
\end{tabular}

Table 4. Chemical composition on the surface of the brittle fracture - point 2 (the stem fragment as seen from the head).

\begin{tabular}{|l|l|l|l|l|}
\hline Element & $\begin{array}{l}\text { Weight } \\
(\mathbf{w t .} \%)\end{array}$ & $\begin{array}{l}\text { Weight \% Error } \\
( \pm \mathbf{1 - \sigma})\end{array}$ & $\begin{array}{l}\text { Atom } \\
(\text { at. \%) }\end{array}$ & $\begin{array}{l}\text { Atom \% Error } \\
( \pm \mathbf{1 - \sigma})\end{array}$ \\
\hline $\mathrm{C}$ & 5.85 & 0.47 & 19.72 & 1.59 \\
\hline $\mathrm{N}$ & 4.26 & 0.86 & 12.29 & 2.49 \\
\hline $\mathrm{O}$ & 1.22 & 0.76 & 3.07 & 1.93 \\
\hline $\mathrm{Al}$ & 0.36 & 0.07 & 0.53 & 0.11 \\
\hline $\mathrm{Si}$ & 0.64 & 0.11 & 0.92 & 0.15 \\
\hline $\mathrm{S}$ & - & - & - & - \\
\hline $\mathrm{Cl}$ & - & - & - & - \\
\hline $\mathrm{K}$ & - & - & - & - \\
\hline $\mathrm{Ca}$ & - & - & - & - \\
\hline $\mathrm{Cr}$ & 19.46 & 0.39 & 15.13 & 0.30 \\
\hline $\mathrm{Mn}$ & 3.79 & 0.48 & 2.79 & 0.35 \\
\hline $\mathrm{Fe}$ & 53.78 & 0.77 & 38.92 & 0.56 \\
\hline $\mathrm{Ni}$ & 8.04 & 0.61 & 5.53 & 0.42 \\
\hline $\mathrm{Mo}$ & 2.60 & 0.20 & 1.10 & 0.08 \\
\hline & 100 & & 100 & \\
\hline
\end{tabular}

In order to confirm the time and cause of the crack development, a qualitative and quantitative analysis was performed in microareas (Figs 10 and 11). It was performed at point 1 - located in the delaminated space which developed as a result of forging (and, at the same time, the area that should be made of a solid material) and at point 2 - at the surface of the fracture (Tabs 3 and 4). At point 1, the levels of carbon, nitrogen and oxygen were significantly higher, while the levels of chromium and iron were lower than the ones reported by the material manufacturer. As compared to the percentage by weight of the M30NW austenitic steel, the following elements are present: aluminium, chromium, sulphur, potassium and calcium. Large contents of oxygen and carbon indicate the presence of oxides, respectively, that might have 
caused the initial crack. At point 2, there are increased levels of carbon, nitrogen and oxygen, which are still lower than at point 1 . The contents by weight of the elements that make austenitic steel, i.e., chromium, nickel, manganese and molybdenum, is approximately in line with the manufacturer's data. Both in point 1 and 2, there is aluminium and chromium in small amounts. Such elements as sulphur, chlorine, potassium and calcium, which do not occur in austenitic steel and are present in the delaminated space developed as a result of forging, prove the entry of systemic fluids and a defective technological process. The most probable process that led to the fatigue fracture of the neck of the Aura II stem under examination is the one related to material defects in the process of casting and forging (forging the material with delamination and the presence of brittle oxides and carbides), which caused a significant reduction in strength and resistance to corrosion.

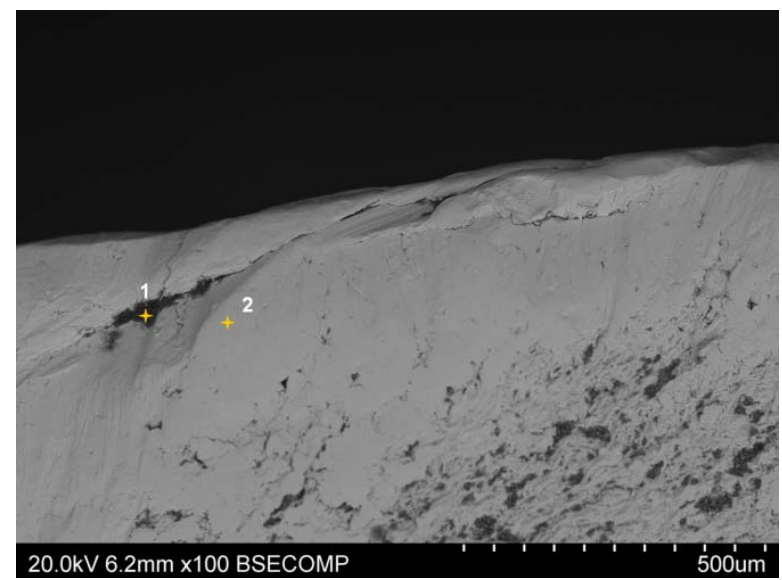

Fig.10. A SEM image of the forging zone with the chemical composition analysis points marked.

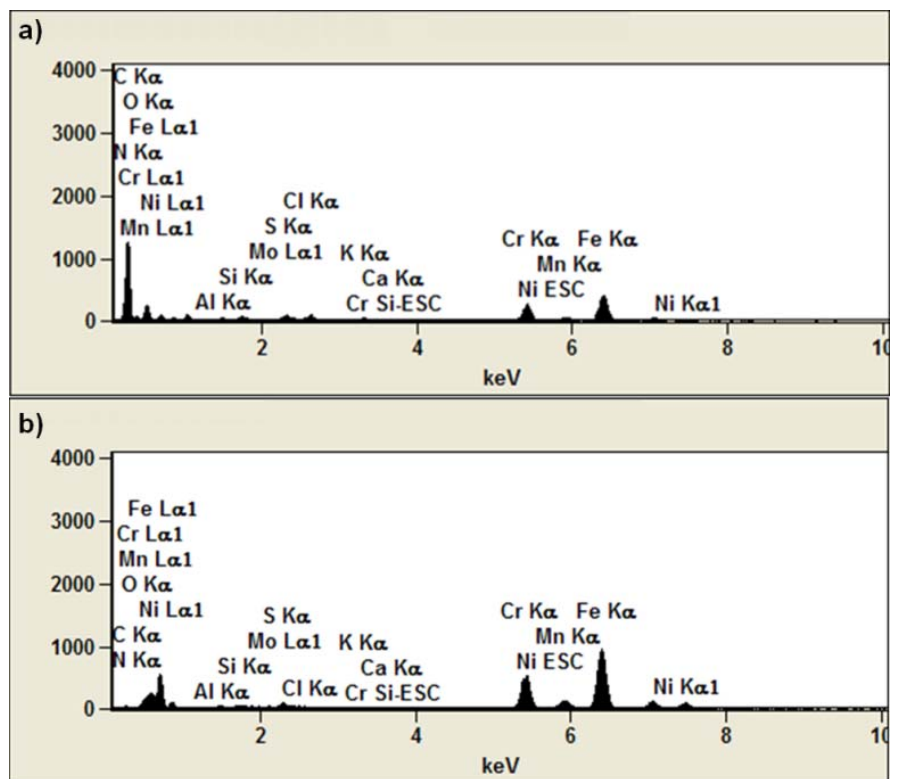

Fig.11. The chemical composition analysis in the stem neck: a) the forging zone - point 1, b) the brittle fracture zone - point 2. 


\section{Conclusion}

A spontaneous endoprosthesis stem fracture is among the rarest complications of the hip replacement surgery. In the case under examination, the implant insertion procedure was performed correctly. The information presented here focuses on the biomechanical conditions, the material and technologies used to manufacture the Aura II stem. A simulation of the distribution of the reduced stresses and resultant dislocations in the hip zone with the Aura II system prosthesis while standing on two legs was carried out. The material parameters provided by the M30NW steel producer should have ensured immediate and fatigue strength for the designed neck cross-section. The stem removed from the patient in revision surgery was examined. The visual and scanning evaluation indicated material and technological defects. The surface layer has numerous foci of pitting corrosion, which confirms that the material used to produce the implant has lower resistance to corrosion. Apart from corrosion changes, there were numerous circumferential scratches of the stem neck and the crack of the neck in the direct vicinity of the fatigue fracture and its focus. The fracture of the stem neck has the typical characteristics of a fatigue fracture with the focus, the focal zone, the fatigue zone, the transition zone and the immediate fracture. The crack on the neck circumference which joins the fatigue fracture zone of the stem neck confirms an extensive material defect which occurred at the stage of casting and forging preparation. In SEM images, the characteristic forging of the material makes the fatigue fracture initiation area. The analysis carried out in the focus of the fatigue fracture indicates that the most probable cause of the process that led to the fatigue fracture of the neck of the Aura II stem under examination was material defects in the process of casting and forging (forging the material with delamination and the presence of brittle oxides and carbides), which caused a significant reduction in strength and resistance to corrosion.

In the light of the above, it must be stated that the fracture was caused by material and technological defects of the implanted stem and the entire responsibility for the event that occurred and the exposure of the patient's health and life to risk rests with the producer. In the information provided, the producer claims that the ratio of such events as fractures of cement stems of Aura II hip joint endoprostheses is $0.006 \%$. This information, in the light of an unprecedented neck fracture, should be an indication for non-destructive tests of ready-made stems aiming to discover the material and technological defects that may arise in the process of casting and drop forging.

\section{References}

[1] NFZ - Statistics of JGP 2009 and 2010. http://prog.nfz.gov.pl/app-jgp/ . 2011.

[2] Affatato S., Ruggiero A. and Merola M. (2015): Advanced biomaterials in hip joint arthroplasty. A review on polymer and ceramics composites as alternative bearings. - Composites Part B: Engineering, vol.83, pp.276283.

[3] Phedy P., Ismail H.D., Hoo C. and Djaja Y.P. (2017): Total hip replacement: A meta-analysis to evaluate survival of cemented, cementless and hybrid implants. - World Journal of Orthopedics, vol.8, No.2, pp.192.

[4] Ollivere B., Darrah C., Barker T., Nolan J. and Porteous M.J. (2009): Early clinical failure of the Birmingham metal-on-metal hip resurfacing is associated with metallosis and soft-tissue necrosis. - Journal of Bone \& Joint Surgery, British Volume, vol.91, No.8, pp.1025-1030.

[5] Klein G.R., Levine B.R., Hozack W.J., Strauss E.J., D'Antonio J.A., Macaulay W. and Di Cesare P.E. (2007): Return to athletic activity after total hip arthroplasty: consensus guidelines based on a survey of the Hip Society and American Association of Hip and Knee Surgeons. - The Journal of Arthroplasty, vol.22, No.2, pp.171-175.

[6] Chatterji U., Ashworth M.J., Lewis P.L. and Dobson P.J. (2005): Effect of total knee arthroplasty on recreational and sporting activity. - ANZ Journal of Surgery, vol.75, No.6, pp.405-408.

[7] Söderman P., Malchau H., Herberts P. and Johnell O. (2000): Are the findings in the Swedish National Total Hip Arthroplasty Register valid?: A comparison between the Swedish National Total Hip Arthroplasty Register, the 
National Discharge Register, and the National Death Register. - The Journal of Arthroplasty, vol.15, No.7, pp.884-889.

[8] Malchau H., Herberts P., Eisler T., Garellick G. and Söderman P. (2002): The Swedish total hip replacement register. - J. Bone Joint Surg. Am, vol.84, No.2, pp.S2-S20.

[9] Hailer N.P., Garellick G. and Kärholm J. (2010): Uncemented and cemented primary total hip arthroplasty in the Swedish Hip Arthroplasty Register: evaluation of 170,413 operations. - Acta Orthopaedica, vol.81, No.1, pp.34-41.

[10] Suckel A., Geiger F., Kinzl L., Wulker N. and Garbrecht M. (2009): Long-term results for the uncemented Zweymuller/Alloclassic hip endoprosthesis: a 15-year minimum follow-up of 320 hip operations. - The Journal of Arthroplasty. vol.24, No.6, pp.846-853.

[11] Kotela A., Ambroziak P. and Deszczyński M.J. (2012): Fracture of the hip joint endoprosthesis - case report Sharp Duty, vol.5, pp.1-2.

[12] Yates P.J., Quraishi N.A., Kop A., Howie D.W., Marx C. and Swarts E. (2008): Fractures of modern high nitrogen stainless steel cemented stems: cause, mechanism, and avoidance in 14 cases. - The Journal of Arthroplasty, vol.23, No.2, pp.188-196.

[13] Jarvi K. and Kerry R.M. (2007): Segmental stem fracture of a cemented femoral prosthesis. - The Journal of Arthroplasty. vol.22, No.4, pp.612-616.

[14] Harvie P., Haroon M., Henderson N. and El-Guindi M. (2007): Fracture of the hydroxyapatite-ceramic-coated JRI-Furlong femoral component. - Bone \& Joint Journal, vol.89, No.6, pp.742-745.

[15] Wroblewski B.M., Siney P.D. and Fleming P.A. (2016): Fracture of the stem. In Charnley Low-Frictional Torque Arthroplasty of the Hip. - Springer International Publishing, pp.187-201.

[16] Busch C.A., Charles M.N., Haydon C.M., Bourne R.B., Rorabeck C.H., Macdonald S.J. and McCalden R.W. (2005): Fractures of distally-fixed femoral stems after revision arthroplasty. - Bone \& Joint Journal, vol.87, No.10, pp.1333-1336.

[17] Efe T. and Schmitt J. (2011): Analyses of prosthesis stem failures in noncemented modular hip revision prostheses. - The Journal of Arthroplasty, vol.26, No.4, pp.665-e7.

[18] Drobniewski M., Sibiński M., Plebański R. and Synder M. (2010): Fracture of the endoprosthesis as a rare complication of the hip arthroplasty - a description of two cases. - Chir Narz Ruchu Ortop Pol, vol.75, pp.5356.

[19] Ryniewicz A.M., Madej T., Ryniewicz A. and Bojko Ł. (2016): A Biometrological Procedure Preceeding the Resurfacing. - Metrology and Measurement Systems, vol.23, No.1, pp.97-106.

[20] Ryniewicz A., Ryniewicz A.M., Madej T., Sładek J. and Gąska A. (2013): Biometrological method of pelvis measurement and anatomical positioning of endoprosthesis of hip joint. - Metrology and Measurement Systems, vol.20, No.1, pp.17-26.

[21] Korkmaz O., Bozkus F.S., Aykut U.S., Caki H.C. and Kaygusuz M.A. (2012): The effect of component position on clinical outcomes in resurfacing hip arthroplasty. - Acta Orthopaedica et Traumatologica Turcica, vol.46, No.1, pp.13-16.

[22] http://www.biometorthopaedics.ch/resource/16323/pricelist.pdf

[23] www.stainless.eu/assets/files/produits/en/stainless-bars-M30NW.pdf

[24] Ryniewicz A.M. and Madej T. (2017): FEM analysis in the hip joint reconstructed with classical and modified hip resurfacing. - Engineering Transactions, vol.65, No.1, pp.123-131.

[25] Ryniewicz A.M. (2011): Identification, modelling and biotribology of human joints. - AGH University of Science and Technology Press, Kraków.

[26] Cilingir A.C. (2010): Finite element analysis of the contact mechanics of ceramic-on-ceramic hip resurfacing prostheses. - J Bionic Eng, vol.7, No.3, pp.244-53. 
[27] Walicka A. (2012): Inertia effects in porous squeeze film biobearing with rough surfaces lubricated by a powerlaw fluid. - Special Topics \& Reviews in Porous Media: An International Journal, vol.3, No.3, pp.247-256.

[28] Cwanek J. (2009): The usability of the surface geometry parameters for the evaluation of the artificial hip joint wear. - Rzeszów University Press.

[29] Szala G. and Ligaj B. (2014): Models of fatigue life curves in fatigue life calculations of machine elements examples of research. - Science notebooks. Transport / Silesian University of Technology, vol.82, pp.251-259.

[30] Norman P., Iyengar S., Svensson I. and Flivik G. (2014): Fatigue fracture in dual modular revision total hip arthroplasty stems: failure analysis and computed tomography diagnostics in two cases. - The Journal of Arthroplasty, vol.29, No.4, pp.850-855.

Received: September 20, 2017

Revised: September 27, 2017 